\title{
O PROJETO POLÍTICO PEDAGÓGICO E A CONSTRUÇÃO DA AUTONOMIA E DA DEMOCRACIA NA ESCOLA NAS REPRESENTAÇÕES SOCIAIS DOS CONSELHEIROS
}

\author{
LUCIANA Rosa MARQues
}

\begin{abstract}
RESUMO: $\mathrm{O}$ trabalho aqui exposto se propõe a apreender como um objeto de política, a elaboração do projeto político-pedagógico, ganha materialidade no locus onde é implantado: a escola. Para tal, foi utilizada a teoria das representaçōes sociais proposta por Moscovici e seus seguidores, a partir do entendimento de que as diretrizes da política educacional ganham corpo pelos que a executam. A pesquisa empírica realizou-se na Rede Municipal de Ensino do Cabo de Santo Agostinho, Região Metropolitana do Recife, coletando-se as informaçōes com os membros dos Conselhos Escolares. A partir das representações sociais dos conselheiros, buscou-se verificar como o projeto político-pedagógico é entendido, sua relação com a construção da autonomia da escola, além do seu papel na instituição de relações democráticas no cotidiano escolar.
\end{abstract}

Palavras-chave: Projeto político-pedagógico. Conselho Escolar. Representações sociais. Autonomia. Democracia.

\section{THE POLITICAL PEDAGOCICAL PROJECT AND THE CONSTRUCTION OF SCHOOL AUTONOMY AND DEMOCRACY IN THE SOCIAL REPRESENTATIONS OF THE SCHOOL COUNCILORS}

ABSTRACT: This paper aims at seizing as a political object, the elaboration of the political-pedagogical project, which acquires substance in the locus where it is implemented: school. For this, it turns to the theory of social representations proposed by Moscovici and his followers, who understand that the guidelines of the educational politics are given shape by those who put it into practice. The empirical research was made in the Rede Municipal do Cabo de Santo Agostinho, in the greater Recife, Pernambuco, by

Mestre em Educação pela Universidade Federal de Pernambuco (UFPE) e doutoranda em

Sociologia pela mesma instituição.E-mail: lu_marques@terra.com.br

Educ. Soc., Campinas, vol. 24, n. 83, p. 577-597, agosto 2003 
collecting information from the members of the School Councils. The social representations of these councilors allowed us to find how the political pedagogical project is understood, as well as its relationship to school autonomy and its function in the democratic relation in the school daily reality.

Key words: Political pedagogic project. School council. Social representations. Autonomy. Democracy.

$E$

ste artigo expóe os resultados de uma pesquisa ${ }^{1}$ realizada em escolas da rede pública, que se propôs a apreender como a elaboração do projeto político-pedagógico, um objeto de política, ganha materialidade no locus onde é implantada: a escola. Para tal, foi utilizada a teoria das representações sociais proposta por Moscovici e seus seguidores, segundo a qual as diretrizes da política educacional ganham corpo pelos que a executam, podendo tomar, assim, direções diferenciadas. Com base nas representações sociais dos conselheiros, buscou-se verificar como o projeto político-pedagógico é entendido, sua relação com a construção da autonomia da escola, além do seu papel na instituição de relações democráticas no cotidiano escolar. Dessa forma, procurou-se perceber se os pressupostos que norteiam a política de descentralização da gestão escolar (a desresponsabilização do Estado para com as políticas sociais) estão se efetivando ou se essas diretrizes estão ganhando materialidade em sentido contrário, resultando, assim, na construção de relações democráticas na escola.

\section{As políticas de descentralização}

A discussão sobre a descentralização da gestão educacional é apropriada ${ }^{2}$ pelo governo federal, tendo em vista os novos padrōes de regulação estatal. A adoção dos pressupostos neoliberais pelo poder central traz em seu bojo a exigência de um novo padrão de intervenção estatal, que se explicita no chamado "Estado Mínimo". Tal movimento, experimentado em escala mundial, aparece como justificativa de adequação do aparelho administrativo aos requerimentos da nova ordem econômica.

A partir da década de 1970, o modelo keynesiano de Estado do Bem-Estar Social começa a viver uma crise fiscal e política, ao mesmo tempo que são inauguradas transformaçôes na base da economia capitalista, derivadas, principalmente, do uso da microeletrônica e da informática, além do avanço das telecomunicaçōes. Nes- 
se cenário, as forças neoliberais passam a requerer um novo padrão de intervenção estatal, calcado na desresponsabilização do Estado pelas políticas sociais.

No caso brasileiro, em que o Estado de Bem-Estar nem sequer foi implantado, a ineficiência e o gigantismo da máquina esta$\mathrm{tal}^{3}$ são apresentados como justificativa às reformas que vêm sendo colocadas em curso. O governo prega a necessidade de um Estado moderno e eficiente em face das exigências mundiais (Dowbor, 1997).

Neste sentido, ele deve, paulatinamente, delegar a responsabilidade pelas atividades de educação, saúde e assistência social às esferas do poder local via descentralização, ou contratar os serviços de organizações públicas não-estatais e entidades privadas para realizar essas atividades. A descentralização é apresentada como uma das metas das reformas implantadas: deve-se fortalecer o espaço local, como maneira de garantir eficiência na oferta dos serviços (Pimenta, 1998; Bresser Pereira, 1996).

A reforma administrativa brasileira insere-se nas soluções concebidas pelo governo para o ajustamento do país aos novos requerimentos e às exigências feitos pelos modelos econômicos e políticos, plasmados pelas novas marcas do processo de acumulação. Suas principais características são:

- Descentralização política por meio da transferência de recursos e atribuições para os níveis políticos regionais e locais;

- Descentralização administrativa por meio da delegação de autoridade aos administradores públicos, que se transformam em gerentes progressivamente autônomos;

- Organizações com poucos níveis hierárquicos em vez de piramidal;

- Organizações flexíveis no lugar de unitárias e monolíticas, nas quais as idéias de multiplicidade, de competição administrativa e de conflito tenham lugar;

- Pressuposto de confiança limitada e não de desconfiança total;

- Definição dos objetivos a serem atingidos na forma de indicadores de desempenho, sempre que possível, quantitativos, que constituirão o centro do contrato de gestão entre o mi- 
nistro e o responsável pelo órgão que está sendo transformado em agência;

- Controle por resultados, a posteriori, em vez do controle rígido, passo a passo, dos processos administrativos;

- Administração voltada para o atendimento do cidadão, em vez de auto-referida (Bresser Pereira, 1996, p. 272).

Assim, o que se está procurando estabelecer em nosso país é um replanejamento institucional, inspirado tanto no neoliberalismo quanto nas práticas de gestão industrial, com base nos pressupostos da qualidade total. Procura-se, portanto, privilegiar a administração por projetos, com objetivos estabelecidos previamente, de base local (expressos no processo de descentralização) e altamente competitivos. No entanto, nos espaços locais, começam a ser observados núcleos de resistência a esse modelo gerencial imposto pelas reformas em curso.

No setor educacional, a descentralização, a democratização da gestão escolar e a autonomia da escola aparecem muitas vezes de forma correlata, inclusive sendo encontradas como "sinônimas", tanto em documentos oficiais como na literatura que aborda o tema. Os instrumentos de construção de uma escola pública democrática, segundo esses documentos, são os projetos político-pedagógicos e os Conselhos Escolares. Estes são uma instância de decisão colegiada com a função de gerir a escola democraticamente, representando os diferentes segmentos da comunidade escolar, com papel ativo na construção de seu projeto político-pedagógico, em sua implantação, acompanhamento e avaliação sistemática.

A questão da democratização da gestão escolar e educacional, embora ganhe destaque quando passa a compor a agenda neoliberal, vem sendo discutida, há algum tempo, pelos que se posicionam em perspectiva oposta ao modelo adotado pelo poder central. Tal fato pode demonstrar que a descentralização traz a possibilidade do estabelecimento de diferentes relaçôes no interior da escola, da discussão coletiva sobre a função social desta, da participação dos diferentes segmentos em sua gestão, enfim, possibilita inovações na busca de uma escola pública de qualidade, que atenda aos interesses da maioria da população. Não obstante ser essa descentralização implantada com base nos pressupostos neoliberais, nos quais não se observa preocupação com o alargamento dos direitos sociais. 
A idéia de descentralização, que sempre foi identificada com aspiraçōes por maior participação nas decisōes e, portanto, com práticas democráticas substantivas, vem sendo ressignificada. Isso decorre do êxito cultural e ideológico do neoliberalismo, que se expressa no convencimento da inexistência de outras alternativas de desenvolvimento, que foram amplamente difundidas pelas elites políticas, enraizando a crença da inevitabilidade de novos modos de (des) regulação social. Com efeito, até o sentido das palavras foi ressignificado. A noção de "gestão", utilizada por nós em contrapartida à de administração, visando a contemplar as dimensões política, técnica e pedagógica da administração escolar, passa a ser utilizada no sentido de gerência, a fim de garantir e eficiência do sistema educacional. Da mesma forma, o conceito de descentralização adquire um sentido diferenciado na agenda neoliberal. Quando utilizado em uma perspectiva crítica, é entendido como um processo de construção de uma escola pública democrática, autônoma, universal e de qualidade, que atenda aos interesses da maioria da população brasileira. Ele possibilita, assim, uma relação diferenciada com o espaço público, além da formação da cidadania e do aprendizado democrático, o que envolveria, portanto, partilha de poder.

No discurso neoliberal, observamos o entendimento da descentralização como a delegação de tarefas e decisōes periféricas às esferas locais (escolas), sob rígida fiscalização e controle. Além disso, argumenta-se que, em face da crise do Estado, não é possível dar conta, de forma eficiente, das demandas sociais. Logo, o governo repassa a responsabilidade às escolas, a fim de que cumpram sua finalidade de oferecer educação de qualidade à população brasileira. Podemos, portanto, caracterizar essas iniciativas como de desconcentração, haja vista que é um movimento de "cima para baixo", não havendo, na verdade, uma redistribuição do poder no interior do sistema escolar. O que há é uma participação controlada e uma autonomia meramente operacional, aliás necessária, pois é o que garante o atendimento às condiçôes locais sem ameaçar a estabilidade de toda a rede sob o controle da organização focal. Não se pode esquecer, portanto, de que nesta perspectiva participar de um dado processo social não significa controlar suas instâncias decisórias.

Entendemos, neste estudo, que a política educacional é fruto da ação humana, ganhando materialidade no cotidiano escolar, podendo tomar sentido diferente do proposto pelos fazedores de polí- 
tica. Em perspectiva semelhante, a autonomia será abordada como conquista dos seres humanos que compõem o coletivo da escola. Dessa forma, a escola não é autônoma como uma instituição em si, mas como construção dos sujeitos que a integram (Barroso, 1998; Silva, 1996).

A partir dessa compreensão, optou-se pela teoria das representaçóes sociais para o desenvolvimento do trabalho, por ser uma categoria de análise que investiga como se formam e funcionam os sistemas de referência que utilizamos para classificar as pessoas e os grupos e para interpretar os acontecimentos da vida cotidiana. As representações sociais são sistemas interpretativos da realidade que regem as relações dos indivíduos com o meio físico e social, determinando os comportamentos e as práticas desses indivíduos. A representação é um guia para a ação, orienta as práticas e relações sociais.

Partimos de duas suposições: a primeira é que, mesmo com condiçôes legais, a autonomia só se dará se os sujeitos assim desejarem, podendo tomar sentido diferente do proposto pelos fazedores de política; a segunda é que as aspiraçôes, os desejos, as vontades e experiências do coletivo se conformam em sua instância representativa, que é o Conselho Escolar.

O Conselho Escolar apresenta características interessantes para o desenvolvimento deste estudo: é formado pelos diferentes grupos da comunidade escolar e, ao mesmo tempo, constitui-se como um grupo na escola. A teoria das representaçôes sociais indica que os sujeitos constroem suas representações a partir de sua inserção no todo social, bem como mostra que um grupo é constituído por manter uma determinada relação com o objeto de representação, construindo, assim, as próprias representaçōes. Dessa forma, propusemo-nos a realizar uma abordagem comparativa horizontal ${ }^{4}$ (Spink, 1995) entre esses grupos, a fim de verificar o que é mais importante: o grupo representado ou a participação do sujeito no grupo de conselheiros da escola.

\section{O percurso metodológico}

Foram pesquisadas três escolas da rede municipal de ensino do Cabo de Santo Agostinho, município da Região Metropolitana do Recife. A escolha desse município se deveu à composição de for- 
ças da gestão municipal, que se apresentam no campo progressista popular. Isso sugere que as diretrizes de democratização da gestão escolar não estão coadunadas com os princípios adotados pelo poder central, de desresponsabilização do poder público pelos serviços sociais, como prega a agenda neoliberal, seguida pelo governo federal, mas atendem a uma demanda antiga de trabalhadores em educação e de estudiosos do tema "a busca de uma escola pública universal de qualidade".

Nosso intuito era perceber como essas políticas poderiam ser ressignificadas. Entendíamos que no município, mesmo ele tendo que se enquadrar nas exigências do poder central, até como forma de viabilizar o recebimento de recursos federais, as diretrizes de democratização da gestão não seguiam a orientação neoliberal de desresponsabilização para com as políticas sociais, e sim a orientação que defende a construção de uma escola pública democrática de qualidade, contribuindo para a "aprendizagem que forma o cidadão crítico e coletivo” (Cabo de Santo Agostinho, 2000, p. 11).

Acreditávamos, assim, que a gestão democrática da educação, no município estudado, abriria a possibilidade para que se construísse uma escola pública de qualidade, que atendesse aos interesses da maioria da população brasileira, além de representar uma possibilidade de vivência e aprendizado da democracia. Buscamos, portanto, verificar o caminho diferenciado que as políticas de democratização/descentralização podem tomar daquele que é proposto pelos fazedores da política neoliberal.

O plano municipal de educação considera que o fortalecimento do poder local e da autonomia da escola

é um princípio que deverá ser perseguido para que diferentes unidades escolares construam seu próprio projeto pedagógico e institucional reduzindo os controles e limites centrais que possam entravar os avanços na qualidade do ensino para todos. Em realidades tão desiguais, impôe-se a necessidade de estimular a criação de modelos diferenciados e flexíveis de organização escolar que desenvolvem formas próprias de autogestão pedagógica e educativa com a comunidade. Ter poder de decidir, conhecer a realidade dos alunos, avaliar resultados, definir soluçôes. (Secretaria de Educação do Cabo de Santo Agostinho, 1997, p. 12)

A democratização da gestão escolar é uma diretriz que, pelo seu grau de importância, conforme exposto no plano municipal de educação, foi transformada em projeto. Assim, 
democratizar a gestão das escolas implica condições de autonomia técnica, financeira e pedagógica para que as escolas possam administrar seu projeto educativo com responsabilidade. Os Conselhos Escolares, Associação de Pais de Alunos, Grêmios Estudantis exigem a instalação de um processo de discussão e de informações para a escolha dos dirigentes municipais, para avaliação da produtividade da escola, da aprendizagem dos alunos, por se considerar que um ensino de qualidade passa pela qualificação da demanda e por uma gestão escolar colegiada. (Idem, ibid., p. 20)

Os critérios de escolha das escolas estudadas foram existir o Conselho Escolar e discutir o projeto político-pedagógico há, no mínimo, dois anos. A rede municipal, no período da coleta dos dados, estava em processo de capacitação ${ }^{5}$ sobre o projeto político-pedagógico para a implantação deste em toda a rede. As três escolas foram escolhidas porque, anteriormente às deliberações dos gestores municipais, já vinham, havia aproximadamente dois anos, discutindo seus projetos político-pedagógicos, embora de forma não sistematizada.

Todas as escolas pesquisadas contam com Conselho Escolar, composto por representantes de pais, alunos, professores, funcionários, sociedade civil organizada e direção, funcionando desde 1997. Isso conforme determinação da política municipal de educação, que apresenta como uma de suas ações prioritárias a implantação de Conselhos Escolares ou entidades semelhantes nas escolas municipais.

Nessas escolas, os Conselhos Escolares funcionam, ainda, como Unidades Executoras (exigência do governo federal para o envio de recursos às Unidades Escolares), sem perder, no entanto, conforme depoimento dos entrevistados, a sua função de unidade gestora da escola. Segundo os entrevistados, o município compreendeu que as atribuições das Unidades Executoras estariam entre as do Conselho, que são mais amplas. Por isso, os Conselhos Escolares já instalados e regulamentados absorveram as atribuiçôes das Unidades Executoras. A nosso ver, essa é uma determinação bastante interessante na medida em que o aspecto gestor suplanta o executor. Os Conselhos Escolares, como unidades gestoras da escola, têm um papel bem mais amplo do que decidir a utilização das verbas e a posterior fiscalização. A gestão dos recursos financeiros pelo coletivo da escola é importante e inclui-se na gestão da escola, que é, porém, mais ampla e ultrapassa os limites do financeiro, abarcando, assim, o todo da escola. 
A amostra foi composta de 23 sujeitos assim distribuídos, por segmento: 4 dirigentes, 4 professores/professoras, 4 pais/mães, 5 alunos/alunas, 2 funcionários/funcionárias, 2 membros da comunidade civil organizada.

$\mathrm{Na}$ abordagem dos sujeitos foram utilizadas três técnicas. A primeira foi a associação livre, quando se pedia a cada entrevistado que escrevesse as palavras e/ou expressões que lhe vinham à mente com a "palavra" indutora projeto político-pedagógico. Com esta técnica, visava-se à atualização dos elementos implícitos ou latentes da representação em virtude de seu caráter pouco controlado (Abric, 1992). Na análise, as unidades de significação apresentadas foram agrupadas em categorias e analisadas por meio de gráficos de freqüência.

A segunda técnica utilizada foi a entrevista, que visava a contemplar as seguintes questôes: o que é um projeto político-pedagógico; qual a sua utilidade; como foi elaborado o projeto da escola; o que é a autonomia escolar e qual a sua relação com o projeto político-pedagógico. Segundo Minayo (1994, p. 47):

O que torna a entrevista instrumento privilegiado de coleta de informaçôes para as ciências sociais é a possibilidade de a fala ser reveladora de condições estruturais, de sistemas de valores, normas e símbolos (sendo ela mesma um deles) e, ao mesmo tempo, ter a magia de transmitir, através de um porta-voz, as representações de grupos determinados, em condições históricas, socioeconômicas e culturais específicas.

As entrevistas foram analisadas a partir das considerações de Bardin (1977) sobre a análise da enunciação. Segundo ele, por trás do discurso aparente, geralmente simbólico e polissêmico, escondese um sentido que convém desvendar. Assim, o discurso foi tomado como momento de confrontação de motivações, desejos e investimentos com as imposições do código lingüístico. Tenta-se, por meio da fala dos sujeitos, reconstruir seus investimentos, suas atitudes e representações.

Para isso, as entrevistas foram agrupadas, por segmento, segundo quatro estruturas temáticas: o significado do projeto; seu processo de elaboração; a autonomia da escola; e sua relação com o projeto político-pedagógico. Isso foi feito com o fim de se perceber os sentidos hierarquizados em cada uma delas, suas contradições, sua estrutura interna, enfim, os componentes da representação social. 
Por último, solicitou-se a cada entrevistado que realizasse um desenho de uma escola autônoma. Com esse procedimento buscouse verificar os elementos constitutivos da autonomia da escola. Após a elaboração do desenho, os sujeitos explicaram suas produçóes. Os desenhos permitem descobrir o conteúdo e formular hipóteses sobre os elementos centrais das representações (Abric, 1992).

Os resultados obtidos por intermédio das três técnicas utilizadas foram comparados, tentando-se perceber se havia o reforço das representaçôes sociais nas diferentes técnicas ou se elas se apresentavam de forma contraditória. Dessa forma, pôde-se perceber os sentidos hierarquizados nas representações de cada segmento, sem desprezar, contudo, suas contradições e os sentidos não recorrentes verificados, por considerá-los constitutivos das representaçóes dos conselheiros.

Nossa análise focalizou como o projeto político-pedagógico - objeto de política educacional que visa à construção da autonomia e à implantação de relações democráticas nas escolas públicas - está sendo representado pelos membros do Conselho Escolar das escolas da Rede Municipal de Ensino do Cabo de Santo Agostinho. Verificamos também o papel desse projeto na democratização da gestão escolar. Tratamos, ainda, a partir das representaçôes sociais dos conselheiros, da relação entre democratização/autonomia da escola e desresponsabilização do poder público na oferta da educação, ou seja, da possibilidade de privatização da rede pública de ensino.

\section{As representações sociais dos conselheiros da escola}

\section{I - Os dirigentes}

Nas representaçóes sociais dos dirigentes sobre o projeto político-pedagógico, observa-se a predominância da representação do projeto como instrumento de planejamento do cotidiano escolar, sendo o planejamento entendido como o "organizador da escola". Não se verificou referência aos pressupostos sociofilosófico-epistemológicos, que, segundo Veiga \& Resende (1998), delineariam as escolhas dos que compõem o coletivo da escola que se quer construir e do cidadão que se deseja formar e representariam uma mudança significativa na forma de planejar o cotidiano da escola. 
No entanto, alguns depoimentos "entram" no campo das emoçôes dos sujeitos que compõem a comunidade escolar, quando expõem suas ansiedades e desejos com relação à escola. Assim, abrem a possibilidade para que o projeto não seja da escola, mas daqueles que a fazem, dos sujeitos que a compõem, tendo em vista que a escola não é uma instituição em si, mas uma instituição composta por seres humanos, cujos fazeres irão construir a identidade dela.

$\mathrm{Na}$ associação livre, os elementos semânticos que deram sentido ao projeto político-pedagógico foram a participação e a qualidade de ensino, aparecendo o planejamento com freqüência um pouco menor. Contudo, não parece que estejamos diante de uma contradição com o que foi posto nas entrevistas, haja vista o aparecimento significativo do planejamento nas associaçōes e a correlação existente, na fala dos diretores, entre o planejamento e a qualidade de ensino.

$\mathrm{O}$ aspecto participativo na elaboração dos projetos das escolas estudadas parece ser o grande avanço que eles representam. Se, até então, tínhamos planejamentos elaborados pela direção ou, no máximo, pela equipe técnica, agora essa realidade parece estar sendo alterada. Conforme o depoimento dos diretores entrevistados, a comunidade escolar participou do processo de elaboração dos projetos político-pedagógicos das escolas. Tal realidade delineia outra feição ao planejamento da escola - função do projeto segundo as representaçôes do segmento em tela - na medida em que ele passa a ser responsabilidade de todos.

Segundo os depoimentos, a Rede Municipal de Ensino do Cabo de Santo Agostinho pôs em prática as diretrizes de sua política educacional porque conseguiu trazer a comunidade escolar como um todo à participação na elaboração dos projetos político-pedagógicos das escolas. Tal experiência não parece estar sendo posta em prática pela maioria dos municípios do estado nem pela Rede Estadual de Ensino, o que nos leva a questionar quais fatores têm contribuído para o êxito do município com relação à participação da comunidade na gestão de suas escolas.

A participação da comunidade na gestão da escola é a principal característica da escola autônoma, expressa nas representaçôes sociais dos dirigentes. Dessa forma, as representaçôes dos diretores reforçam os estudos de Paro (1997) e de Neves (1996), para os quais a participação envolve a partilha de poder na definição dos rumos da escola. A autonomia também é representada pelos dirigentes como a liberdade relativa da escola, ou seja, não depender da Secretaria de Edu- 
cação para resolver questões cotidianas e ter a responsabilidade pela definição, por parte da escola, da utilização dos recursos financeiros a ela destinados.

\section{II - Os professores}

$\mathrm{Na}$ associação livre, os sentidos do projeto político-pedagógico hierarquizados foram o planejamento, a melhoria/o desenvolvimento da escola e a participação, esta com freqüência um pouco menor.

As entrevistas, reforçando o que foi verificado na associação livre, indicam a representação do projeto político-pedagógico como instrumento de planejamento escolar, de melhoria da escola e de participação, conforme ilustra o depoimento a seguir:

Serve para que a gente trabalhe dentro das metas e objetivos que queremos atingir, quer dizer, serve para organizar, de fato, a escola. Todo mundo trabalhando e sabe por que e para que estamos trabalhando, qual a meta que queremos atingir com aquele trabalho (...) foi elaborado por todo mundo da escola, professores, serviços gerais, alunos, todo mundo participou. (Entrevista 11)

As entrevistas indicaram, ainda, que a participação na elaboração do projeto político-pedagógico envolveu conflitos, negociações e acordos, o que vai de encontro ao que foi verificado em pesquisa realizada por Azevedo et al. (1999), ${ }^{7}$ em que a participação na elaboração do projeto se resumia à concordância com o que estava previamente definido pela direção, portanto limitada e, de certa forma, imposta à comunidade, para atender a um requisito burocrático. Esse confronto entre os dois estudos demonstra, de forma clara, como uma mesma medida de política pode traçar caminhos diferenciados, reforçando a argumentação de Barroso (1998) de que a implantação de políticas que visem à construção da autonomia não garante, por si só, que ela seja alcançada. Não existe, assim, uma autonomia decretada, mas uma construção social pela interação dos sujeitos que fazem a escola.

As representações sociais dos professores sobre a autonomia ancoram-se na redefinição das determinações da Secretaria de Educação; na possibilidade de a escola resolver, coletivamente, os problemas enfrentados; e no alcance coletivo de metas. Já a escola autônoma é representada como aquela em que há a participação da comunidade escolar em sua gestão e na construção de sua identidade, não obstante a existência de um eixo central que norteia o fazer pedagógico das es- 
colas públicas, que é a Secretaria de Educação. Por fim, a relação entre a autonomia da escola e o seu projeto político-pedagógico está na construção identitária da escola e na participação do coletivo, como elemento constitutivo da autonomia, na elaboração de seu projeto.

\section{III - Funcionários}

$\mathrm{Na}$ associação livre, o sentido semântico hierarquizado pelos funcionários sobre o projeto político-pedagógico foi o planejamento, seguido da participação, esta com freqüência bem menor. Tais representações sociais do projeto político-pedagógico foram reforçadas nas entrevistas, em que ele aparece como um instrumento de planejamento, elaborado coletivamente. Nas representaçōes apresentadas pelos funcionários, o projeto político-pedagógico é, na realidade, um plano de trabalho com outra denominação. Não há nenhuma referência, por exemplo, aos pressupostos sociofilosóficos que deveriam estar contemplados, embora no texto dos projetos esses pressupostos apareçam na parte em que se concebe a missão da escola.

A autonomia é representada como a liberdade com respeito à hierarquia, ao passo que a relação dela com o projeto políticopedagógico é uma possibilidade de pôr as idéias do coletivo em prática. No entanto, a liberdade apresenta vertentes diferenciadas: ora ela é da direção, ora ela é da escola, como ilustram os depoimentos abaixo:

É quando a direção tem autonomia para decidir algumas coisas. Claro, que se há hierarquia, a própria secretaria tem que intervir, mas também tem coisas que a direção vê que são para o melhoramento do trabalho, têm autonomia para fazer e depois levar o resultado. (Entrevista 4)

Autonomia escolar é a liberdade de você atuar dentro da escola. (Entrevista 2)

Ao passo que o entrevistado 2 ancora a sua compreensão de autonomia na liberdade de atuação no cotidiano escolar, o entrevistado 4 destaca o caráter relativo dessa liberdade que deve respeitar a hierarquia. São também interessantes as diferentes perspectivas de autonomia apontadas: para o entrevistado 4, a autonomia é da direção da escola, que pode resolver as questóes concernentes ao melhoramento da escola sem a intervenção da Secretaria de Educação, que deve ser informada posteriormente. Diferentemente, para o entrevistado 2, a autonomia não é da direção, mas sim da escola. Parece-nos que essa perspectiva apresenta uma melhor 
compreensão do que vem sendo discutido com relação ao tema, tendo em vista que autonomia pressupóe participação e, dessa forma, é relativa à escola e não à figura da direção. Na perspectiva apontada pelo entrevistado 4 , a autonomia restringe-se à independência do diretor com relação aos órgãos superiores de educação, porém o caráter centralizador e hierárquico que vem caracterizando as unidades públicas de educação aparece implícito em sua representação. No entanto, quando solicitamos que ele realizasse um desenho de uma escola autônoma, o entrevistado 4 trouxe à tona a responsabilidade coletiva na construção do espaço escolar, que é o centro, ao qual todos os segmentos convergem suas energias para atingir objetivos comuns.

\section{IV - Membros da comunidade}

$\mathrm{Na}$ associação livre, as representações sociais dos membros da comunidade ancoram-se em melhoria/desenvolvimento da escola e na participação. Isso é reforçado pelas entrevistas, nas quais esses mesmos sentidos do projeto político-pedagógico foram hierarquizados, como pode ser observado no seguinte trecho:

Para mim é bom que a escola venha melhorar mais, que a gente tenha sempre bons alunos. Assim, como a escola antes não tinha esse piso como tem agora, como esse Conselho que tem agora no colégio e chama nós da comunidade. Eu mesma, que sou evangélica, sou chamada porque faço parte da comunidade evangélica, sou chamada pela diretora e, com esse projeto político-pedagógico, teve Conselho na escola para que melhorasse [sic] nossos alunos futuramente e que a escola pudesse ter um futuro melhor, sempre adequado. Eu achei muito interessante esse Conselho no colégio, não somente para mim, mas para todos os membros do nosso Conselho veio muito bem. (Entrevista 19)

Observa-se que a participação não surgiu como uma demanda da comunidade, mas sim como um chamado da direção escolar, havendo a compreensão de que ela representa uma melhoria no cotidiano escolar. No entanto, esse fato não minimiza a participação, haja vista que ela representa uma mudança na relação escola/sociedade. Se a comunidade tem de, inicialmente, ser chamada a estar presente na escola, é bem provável que essa prática se solidifique no sentido da aprendizagem democrática e, em momentos posteriores, a própria comunidade perceba a importância de sua participação, demandando um aumento dessa participação. 
Em pesquisa sobre a participação da comunidade na gestão escolar, Paro (1997, p. 46) demonstra as dificuldades encontradas pela população em participar na escola. Ele propõe, assim, que sejam criados mecanismos institucionais que viabilizem e incentivem essa participação. Parece-nos que, em nosso caso, tal exigência é contemplada. $\mathrm{O}$ chamado da direção à participação da comunidade, com base nas diretrizes definidas no Plano Municipal de Educação, viabiliza essa participação. Dessa forma, a população já começa a considerá-la interessante e, posteriormente, poderá assumi-la como uma solicitação sua, haja vista a possibilidade de compreensão, na prática, dos avanços que ela pode representar na construção da escola pública.

A participação é destacada na elaboração dos projetos, o que indica o caminho da autonomia escolar. Para esse segmento, porém, não existe a relação entre projeto político-pedagógico, participação e autonomia da escola, o que pode ser evidenciado tanto na incompreensão do termo quanto no seu entendimento, de acordo com o sentido utilizado no "senso comum": "Acho que ninguém participa, ninguém conhece as coisas que está [sic] acontecendo. Acho que seja isso. Que não se sabe o que se faz, o que o filho fez" (Entrevista 16).

No depoimento 16, encontram-se referências ao sentido de autonomia utilizado no "senso comum". Autônomo é aquele que não se vincula a outro, é independente, que resolve suas questóes isoladamente sem necessitar recorrer ao auxílio dos outros. Percebe-se, assim, que o sentido de autonomia da escola pública encontrado na literatura gestão democrática, liberdade relativa - não chega à sociedade civil organizada. Mesmo assim, encontramos nas representaçôes sociais dos entrevistados caminhos da autonomia, como, por exemplo, a participação deles na gestão escolar, embora para esse segmento a autonomia não seja compreendida dessa forma.

\section{V - Pais/Mães}

Da mesma forma que no segmento dos representantes da sociedade civil organizada, entre os pais e as mães participantes do Conselho Escolar entrevistados, melhoria e desenvolvimento da escola são o sentido semântico do projeto político-pedagógico que mais se destaca na associação livre. Cumpre ressaltar que, na realidade, aqueles que fazem parte da sociedade civil organizada da comunidade em que se localiza a escola são pais de alunos atendidos 
na escola (o que não aconteceu em nosso caso) ou têm seus filhos atendidos por outra escola pública, mantendo contato e, muitas vezes, sendo da mesma família de pais ou mães de alunos da escola estudada. Essa identificação se materializa na ênfase dada por esses dois segmentos a melhoria/desenvolvimento da escola como o principal significado do projeto político-pedagógico. Parece-nos, portanto, que as representações encontradas se estruturam a partir do grupo social de pertença desses sujeitos e não de sua condição de participante do grupo de conselheiros da escola, embora essa condição também influencie na construção das representações sociais desses sujeitos.

Para o segmento em tela, a representação do projeto como instrumento de melhoria e desenvolvimento da escola aparenta estar sedimentada. Pode-se inferir que essa compreensão deriva da relação que os pais e as mães têm com a escola. $\mathrm{Na}$ realidade, os usuários da escola são os filhos e, por conseguinte, estes também são os mais prejudicados com os problemas encontrados na rede pública de ensino. Assim, a grande demanda desse segmento, que se reflete em suas representações, prima por uma escola de qualidade, que atenda aos seus interesses educacionais.

Acreditamos que a prática participativa nas Unidades Escolares pode contribuir no aprendizado de novas relaçóes com o poder público, auxiliando a população a reconhecer-se como um agente político. Neste sentido, o depoimento transcrito a seguir indica a presença da comunidade escolar na gestão da escola: "Na elaboração do projeto a gente reuniu todos os membros da escola. Todos os projetos que acontecem na escola o Conselho Escolar está sempre presente." (Entrevista 12).

A presença do Conselho Escolar no cotidiano da escola representa uma nova forma de gerir as instituições públicas de ensino, porquanto ele é composto por todos os segmentos da comunidade escolar e também de representantes da sociedade civil organizada. Dessa forma, a escola pode resguardar-se das constantes mudanças na política educacional, realizadas a cada quatro anos com a troca de governo. Um projeto político-pedagógico elaborado coletivamente pela comunidade escolar não é da direção $\mathrm{A}$ ou $\mathrm{B}$, ou do governo $\mathrm{X}$ ou $\mathrm{Y}$, mas sim da escola, que poderá colocá-lo em prática de acordo com a realidade dela, a fim de atender aos interesses dos sujeitos que a compõem. A escola fortifica-se adquirindo melhores condições de lutar por seus anseios e objetivos. 
Com relação à autonomia da escola, as representaçōes sociais dos entrevistados apontam em duas direçōes: a resolução interna de questôes cotidianas e a impossibilidade de as escolas públicas serem autônomas. Os que ressaltam a impossibilidade de escolas da rede pública serem autônomas evocam a responsabilidade do poder público na oferta da educação à população. Tem-se, assim, a compreensão de que a autonomia passa pelo financeiro, não sendo possível, portanto, cogitar-se a idéia de uma escola pública autônoma. Dessa for$\mathrm{ma}$, a preocupação com a privatização do ensino nem sequer existe, pois ela não é nem cogitada: não existe outra possibilidade além do financiamento da educação pública pelo poder estatal.

\section{VI - Alunos}

$\mathrm{Na}$ associação livre, os sentidos semânticos do projeto políticopedagógico mais destacados pelos alunos foram o planejamento, a participação e a qualidade de ensino. Porém, as entrevistas fazem-nos supor que, na realidade, houve uma certa confusão, por parte do corpo discente, entre o projeto político-pedagógico e o Plano de Desenvolvimento da Escola (PDE), conforme se vê na entrevista 15: "Eu acho que é um plano que a escola faz para organizar-se com relação a custos, gastos que vêm da verba do Governo da Secretaria de Educação". (Entrevista 15).

O Plano de Desenvolvimento da Escola é uma exigência do governo federal, dentro do programa FUNDESCOLA, para o envio de recursos à escola, sendo elaborado a partir da definição de metas e estratégias e dos recursos necessários à sua consecução. De acordo com o documento enviado às escolas da Rede Municipal de Ensino para auxílio na elaboração do PDE,

o plano de desenvolvimento da escola é um processo gerencial de planejamento estratégico, desenvolvido pela e para a escola, para a melhoria da qualidade do ensino; auxilia a escola a se organizar de maneira eficiente e eficaz, com a melhor concentração de esforços e recursos para a melhoria do desenvolvimento dos alunos.

O PDE fora elaborado havia pouco tempo, com bastante mobilização das escolas para tal fim, segundo o que foi relatado pelos dirigentes escolares e pela Secretaria de Educação. Parece-nos que, para o corpo discente, não ficou bem clara a diferença entre ele e o projeto político-pedagógico. 
As representações sociais de autonomia, encontradas neste segmento, ancoram-se na história construída pela Unidade Escolar, na integração entre os diferentes segmentos que a compõem e também na compreensão da escola como espaço dos alunos. Este segmento, contudo, não construiu, ainda, representações sobre a relação entre a autonomia e o projeto político-pedagógico.

\section{A que conclusões chegamos}

O estudo das representações sociais dos membros do Conselho Escolar das escolas da Rede Municipal de Ensino do Cabo de Santo Agostinho permitiu-nos perceber que não há vinculação entre democratização da gestão e autonomia da escola e privatização do sistema público de ensino, porque a responsabilidade do Estado para com a educação pública foi reforçada.

Observou-se que a inserção social dos sujeitos entrevistados tem mais importância que a sua participação no grupo conselheiro, pois apareceram diferenças significativas nas representaçóes sociais de pais/ mães e da sociedade civil organizada. No entanto, a participação no grupo conselheiro está influindo na estruturação das representações desses sujeitos.

Com relação ao projeto político-pedagógico, percebe-se que ele não está se constituindo em um instrumento de construção da singularidade das escolas, visto que não encontramos nas representações sociais dos conselheiros referências aos pressupostos sociopolítico-filosóficos que dariam a feição da escola; além disso, em sua maioria, as representações sobre o projeto ancoram-se no planejamento.

$\mathrm{O}$ projeto, porém, indica um grande avanço quando verificamos, consensualmente, que sua elaboração se deu de forma participativa. Participação essa que envolveu conflitos e negociações, resolvidas a partir de decisões majoritárias, indicando uma nova forma de organização escolar, que rejeita o seu caráter hierárquico, historicamente construído. Assim, a elaboração do projeto político-pedagógico constitui-se em um momento de aprendizagem democrática.

No que tange especificamente à autonomia, evidenciou-se ser essa uma discussão que se limita aos profissionais da educação. Para os membros da comunidade, pais, mães e alunos, tal conceito é entendido pelo sentido utilizado no "senso comum". Para os outros segmentos, a autonomia é ancorada na liberdade relativa que a es- 
cola dispõe para resolver suas questões cotidianas. Aqui também se evidencia que a inserção social dos sujeitos suplanta sua participação no grupo conselheiro, na formulação de suas representações sociais. Não há vinculação entre a autonomia e a desresponsabilização do poder público com a educação; ao contrário, a autonomia é relativa, exatamente porque as escolas não podem fugir ao que é determinado pelas diretrizes da política educacional municipal. Dessa, forma, não se pode falar, ainda, de representações sociais do grupo conselheiro.

Percebe-se, portanto, que, apesar de as medidas de política estudadas seguirem as orientações dos organismos internacionais, coadunando-se com os pressupostos neoliberais, é possível construir-se algo positivo a partir das determinações do poder central no locus onde as políticas se materializam: as escolas. Os mecanismos de "descentralização centralizada" impostos pelo poder central criam condiçôes de organização da comunidade escolar, que pode, assim, apropriar-se deles para mudar os rumos da política.

Dessa forma, podemos concluir que o projeto político-pedagógico vem contribuindo na construção da autonomia nas escolas da Rede Municipal de Ensino do Cabo de Santo Agostinho, uma vez que leva a comunidade escolar a participar de seu planejamento. O projeto possibilita, assim, a organização do trabalho da escola calcado na participação coletiva e instituindo práticas democráticas no cotidiano escolar. Essa é, contudo, uma caminhada que está apenas no início e precisa ainda solidificar-se.

\section{Recebido em outubro de 2002 e aprovado em novembro de 2002.}

\section{Notas}

1. Dissertação realizada no Mestrado em Educação da Universidade Federal de Pernambuco (UFPE).

2. A democratização da gestão educacional e escolar, que vinha sendo uma bandeira das esquerdas, ganha força a partir do momento em que passa a ocupar espaço na agenda neoliberal.

3. Vale ressaltar que os atores responsáveis pela constituição desse modelo administrativo, com todas as suas mazelas, derivadas, principalmente, do uso clientelista do referido modelo, estão hoje à frente da defesa do enxugamento da máquina.

4. Os estudos comparativos horizontais focalizam diferentes grupos em um mesmo universo, ao passo que a abordagem comparativa vertical se realiza entre diferentes grupos culturais.

Educ. Soc., Campinas, vol. 24, n. 83, p. 577-597, agosto 2003 
5. Deve-se ter clareza de que essa capacitação pode ter influenciado nas representações apresentadas, assim como, por se tratar de um tema recente, as representaçóes podem, ainda, estar em processo de construção.

6. “O projeto político-pedagógico é de fato um planejamento onde vai constar [sic] os objetivos, as ansiedades, os desejos da escola junto à comunidade” (entrevista 8).

7. Janete M. Lins Azevedo et al., A qualidade do ensino e a politica educacional no Nordeste, Mestrado em Educação da UFPE, Recife, 1999 (relatório de pesquisa).

\section{Referências bibliográficas}

ABRIC, J.C. Methodologie de recueil des représentantions sociales. In: Abric, J.C. Pratiques sociales et représentantions. Paris: PUF, 1992.

BARDIN, L. Análise de conteúdo. Lisboa: Edições 70, 1977.

BARROSO, J. O reforço da autonomia das escolas e a flexibilização da gestão escolar em Portugal. In: FERReiRA, N.S.C. (Org.). Gestão democrática da educação: atuais tendências, novos desafios. São Paulo: Cortez, 1998.

BRESSER PEREIRA, L.C. Crise econômica e reforma do estado no Brasil. São Paulo: Editora 34, 1996.

DOWBOR, L. Reordenamento do poder e políticas neoliberais. In: GaDelHa, R.M.A.F. (Org.). Globalização, metropolização e politicas neoliberais. São Paulo: EDUC, 1997.

MINAYO, M.C. O desafio do conhecimento: pesquisa qualitativa em saúde. 6a ed. São Paulo: Hucitec; Rio de Janeiro: ABRASCO, 1994.

NEVES, C.M.C. Autonomia da escola pública: um enfoque operacional. In: Veiga, I.P. (Org.). Projeto político-pedagógico da escola. Campinas: Papirus, 1996.

PARO, V.H. Gestão democrática da escola pública. São Paulo: Ática, 1997.

PIMENTA, C.C. A reforma gerencial do Estado brasileiro no contexto das grandes tendências mundiais. 1998. Disponível em: <http// www.mare.gov.br>.

PERNAMBUCO. Prefeitura Municipal do Cabo de Santo Agostinho. Plano Municipal de Educação (1997/2000). Cabo de Santo Agostinho, ago. 1997. 
SADER, E. Movimentos sociais na transição democrática. São Paulo: Cortez, 1988.

SILVA, R.C. Projeto pedagógico: a escola em questão. Revista de Administração Educacional, Recife, v. 1, n. 1, 1997.

SPINK, M.J. (Org.). O conhecimento no cotidiano. São Paulo: Brasiliense, 1995.

VEIGA, I.P. (Org.). Projeto político-pedagógico da escola. Campinas: Papirus, 1996.

VEIGA, I.P.; RESENDE, L.M.G. (Org.). Escola: espaço do projeto político-pedagógico. Campinas: Papirus, 1998. 